\title{
A POLÍTICA NAS RUAS: os espaços públicos na cidade imperial do Rio de Janeiro
}

\author{
Marco Morel*
}

Abstract - The political dimension of the public manifestations that happened in the streets of Rio de Janeiro between 1820 and 1840, at the same time considered as city and Court, points out to changes that were occurring in the public spaces during the transition from absolutism to political modernity. The different occupations of the commerce quarters, squares and public places expressed a "dispute" for the prominence of the pólis - political interferences that were delimited by the urban scene predominantly traditional and at the same time tried to interfere and transform it.

A imagem que logo vem à tona quando se fala do Rio de Janeiro na época do Brasil Império é a de Corte, isto é, capital centralizadora, sede da monarquia e do poder imperial, local privilegiado onde as "elites" em geral controlavam as teias do poder. Ou, em modo mais simplificado, a Corte enquanto lugar dos "conchavos", das decisões "por cima", feitas entre quatro paredes. Não se trata de negar as dimensốes centralizadoras que a capital encarnava em termos nacionais, mas tal visão pode acarretar o risco de não permitir a compreensão da complexidade de outros aspectos da vida desta pólis.

A perspectiva do presente trabalho é a de enfocar, através de uma abordagem histórica privilegiando as dimensões políticas, algumas manifestações que se faziam nas ruas, dentro do contexto de trans-

* Professor no Departamento de História da Universidade do Estado do Rio de Janeiro, Brasil.

Estudos Ibero-Americanos. PUCRS, v. XXIV, n. 1, p. 59-73, junho 1998 
formações dos espaços públicos, no quadro urbano do Rio de Janeiro no período entre 1820 e 1840 , época que marca o processo de independência, de consolidação da monarquia e do Estado nacional ${ }^{1}$.

Tal abordagem não esgota a ampla gama de aspectos em torno dos espaços públicos e das formas de sociabilidade urbana e busca sobretudo apontar possíveis pistas, a partir do pressuposto de que a vida política, enquanto vida pública, não se desenrolava apenas em palácios, gabinetes ou dentro das casas, mas também nas ruas (praças, quarteirões, largos, etc.). ${ }^{2}$

\section{Rio, cidade imperial}

A intensa atividade pública que existia nas ruas do Rio de Janeiro no começo do século XIX pode ser dividida, para efeitos puramente didáticos, em duas vertentes. Em primeiro lugar, uma que se poderia chamar de "Antigo Regime", ou seja, os espetáculos de visibilidade do poder monárquico, do qual a Igreja fazia parte, como as missas Te Deum, procissões, festas religiosas e também celebrações dinásticas (aniversários, casamentos, batizados, etc., de membros da dinastia), desfiles de autoridades com paramentos, enfeites e estandartes, cortejos de condenados à morte, aclamações e manifestaçóes de adesão à monarquia, entre outros aspectos. Eram manifestações que envolviam consideráveis parcelas da população e que permeavam o cotidiano da cidade, numa época em que evidentemente não se tratava de uma sociedade industrial de "massas". Após a chegada da Família Real por-

Este artigo foi extraído da minha tese de Doutorado em História (sobretudo dos capítulos 5 e 7) La formation de l'espace publique moderne à Rio de Janeiro (1820-1840): opinion, acteurs et lieux (Université de Paris I, dezembro de 1995). Para uma abordagem geral do conceito de espaço público, ver a obra de Jürgen Habermas Mudança estrutural da esfera pública (Rio de Janeiro: Tempo Brasileiro, 1978).

2 O conceito de sociabilidade vem sendo utilizado nos estudos históricos para abordar a densidade, as características e as transformaçôes das diferentes formas de associação (formais ou informais), dentro de um quadro cronológico e geográfico definido. A principal matriz historiográfica para esta abordagem vem das obras de Maurice Agulhon, entre elas: "Le cercle dans la France bourgeoise 1810-1848". In: Cahier des Annales, Paris, n. 36, 1977; Pénitents et francs-maçons de l'ancienne Provence. Paris: Gallimard, 1968. 
tuguesa em 1808 este gênero de manifestação se reforçou e permaneceu intenso durante os Primeiro e Segundo Reinados, sendo que expressões de caráter religioso existem ainda hoje, embora modificadas. ${ }^{3}$

A segunda vertente aqui considerada da atividade pública nas ruas da pólis inclui um universo quase impalpável (para os historiadores atuais) e por vezes perturbador, e que aparece nos registros como palavras isoladas, gritos, exclamações mais ou menos abafadas, enfim, vozes e gestos, violências e "anarquias" que circulavam pela cidade, oriundos de diversas camadas da população, inclusive do que se chamava de "plebe", "populaça" ou "populacho", ocupando e afetando as ruas e praças da cidade. Era também uma forma de manifestação pública que ocupava e marcava as ruas do Rio de Janeiro. Sem falar de manifestações culturais mais tarde qualificadas como folclóricas, mas que na época não tinham tal conotação. ${ }^{4}$

O Rio de Janeiro não era apenas uma Corte (como Versailles, por exemplo, criada fora do centro urbano), mas ao mesmo tempo cidade e Corte. Uma Corte, real ou imperial, é sempre uma configuração urbana singular. ${ }^{5}$ No caso do Rio de Janeiro, uma das peculiaridades é que a cidade precede a Corte. Quando a capital da América portuguesa foi transferida de Salvador para o Rio, 1763, o espaço urbano já existia. Da mesma maneira em 1808, quando da chegada da Família

3 Estes espetáculos que marcavam a visibilidade do poder monárquico nāo foram ainda objeto de estudos aprofundados em termos de Brasil. Ver a tese de Maria Eurydice de Barros Ribeiro Mémoire d'un empire, le Brésil et La Plata - histoire, historiographie et réprésentations symboliques (Doutorado em História, Université de Paris X, 1990), sobretudo a parte sobre as representações simbólicas. E também a dissertaçâo de William de Souza Martins Do arraial à Corte: festejos e civilizaçāo na cidade do Rio de Janeiro, 1828 -1860 (Mestrado em História, Universidade Federal Fluminense, 1996).

4. Ilmar R. de Matos em O tempo saquarema (Rio de Janeiro: Hucitec, 1987) aborda para o Brasil imperial o que chama de mundo do trabalho e da desordem, associado ao espaço da rua. O livro de Nelson Omegna A cidade colonial (Rio de Janeiro: José Olympio, 1961) contém análises sobre as políticas absolutista e moderna que marcavam ao mesmo tempo a vida urbana. Quanto à abordagem histórica sobre fontes que exprimem as vozes e falas das camadas pobres urbanas ver o brilhante trabalho de Arlette Farge Dire et mal dire - l'opinion publique au XVIIle siècle (Paris: Fayard, 1992). Para uma abordagem clássica das "festas populares" do Rio de Janeiro ver de Mello de Moraes Filho Festas e tradições populares no Brasil (Belo Horizonte: Itatiaia, 1979).

5 Sobre as relaçōes entre Corte, civilizaçāo e cidade, ver a obra de Norbert Elias $A$ sociedade de Corte (Lisboa: Estampa, 1995). 
Real, constantemente percebida como a chegada da civilização ao Brasil. Tal movimento implicava no reforço da polícia, impondo controle mais estrito - aceito de maneira voluntária ou não - aos comportamentos públicos e sociais. A cidade tinha a honra de ser sede da Corte, mas este privilégio significava também transformações. A cidade, com suas trepidações e conflitos, entrelaçava-se com a Corte, topo da hierarquia do poder. Além do mais, o Rio era porto comercial, centro importante do comércio de mercadorias e tráfico de escravos. $\mathrm{O}$ Rio de Janeiro era, assim, uma cidade imperial nos trópicos em pleno século XIX.

As noções de "cidade" e "imperial" têm aqui como referência seus significados antigos. A cidade grega, como se sabe, era o local por excelência onde se reuniam os cidadãos, os homens livres, não submissos a um soberano. As famílias poderosas, as aristocracias oligárquicas, com oráculos, eram ao mesmo tempo governantes e súditos e o advento de um tirano não bastava para enfraquecer a organização e autonomia de uma cidade. A noção de império, sobretudo a partir da experiência latina, aparece ligada à expansão e à centralização de poderes. Indica submissão ou incorporação de territórios e centros de poder a um centro de poder, o Estado-Cidade. O imperator romano tinha poderes consideráveis sobre seus súditos. Assim, entre a (busca de) autonomia cidadã do modelo grego e a potência controladora de centro imperial romano, caracterizava-se o Rio de Janeiro da época aqui citada. ${ }^{6}$

\section{Os comércios ao redor da Corte}

Para caracterização inicial destes espaços urbanos do Rio de Janeiro nada como um passeio num raio de apenas 600 metros, tendo como epicentro o Palácio do Rio de Janeiro (mais tarde Paço Imperial). ${ }^{7}$ Logo em frente passava-se pelo porto marítimo com a alfândega e os armazéns; em seguida vinha o Banco, penetrava-se pelas ruas do

6 Para as noções de "cidade" e "império" consultei Georges Livet e Roland Mousnier (dir.) Histoire générale de l'Europe (PUF, Paris, 1980, v. 1, p. 97-203). Sobre o cenceito de Império no Brasil ver Maria de Lourdes Viana Lyra A utopia do poderoso império (Rio de Janeiro: Sette Letras, 1994).

7 Para este "passeio" utilisei o Plan de la ville de S. Sebastiāo do Rio de Janeiro. 1820. Gravé par Michel. Cote GeD6646 da Bibliothèeque Nationale de France. 
comércio francês e inglês; vinham os hospitais para os pobres, como a Santa Casa da Misericórdia e Nossa Senhora do Parto; ao lado, os dois mercados, de legumes e peixes, com suas cores e odores peculiares; Arsenal do Exército e o cemitério de escravos; a cadeia da cidade; a Escola de Belas Artes e o Quartel de Infantaria.

Esta proximidade entre o que havia de mais nobre e o que havia de mais plebeu fazia com que a Corte do Rio de Janeiro não se configurasse entrincheirada como a Cidade Proibida da China, por exemplo. Evidente que a contigüidade não eliminava as distâncias socialmente estabelecidas. Mas implicava em que os diferentes espetáculos da vida urbana pudessem rivalizar com o espetáculo da monarquia e que houvesse influências recíprocas. A Corte marcando a cidade com suas formas de controle e ao mesmo tempo sendo contornada e permeada por esta, por suas complexidades e mesmo "desordens". Em termos de configuração dos espaços públicos, isso significava um "comércio" (no sentido mais amplo, de trocas) entre interesses privados, econômicos, com a esfera pública enquanto esfera da coisa pública, tida como bem comum. E aponta talvez para uma característica que permanece no Rio de Janeiro, que se caracteriza pela proximidade de grupos distanciados socialmente, pela visibilidade entrelaçada da miséria e do luxo.

Esta relativa "ameaça" que pairava sobre a Corte ajuda a explicar porque a residência da família imperial situava-se fora dos limites urbanos, no Palácio de São Cristóvão ou Quinta da Boa Vista. E convém destacar que no contexto das revoltas e turbulências políticas que marcaram o período das Regências (1831-1840), quando o Rio de Janeiro foi bastante afetado, surgiram pelo menos duas tentativas de tirar da cidade o caráter de capital nacional. ${ }^{8}$ Eram "fraquezas" resultantes destas peculiaridades da cidade imperial brasileira, bastando lembrar, entre outros casos, os diversos conflitos e sedições esparsos, mas constantes, nos anos 1830 que sacudiam a tranqüilidade da capital.

8 Francisco Albuquerque Holanda Cavalcanti, visconde de Albuquerque, procurou o embaixador francês e pediu apoio para o plano de separar o Norte e Nordeste do país em 1831. Da mesma forma, José Bonifácio, Tutor dos príncipes imperiais, pediu ao mesmo embaixador garantias para poder transportar num navio francês, em caso de rebeliāo, o jovem Pedro II, transferindo a capital para São Paulo. Cf. Correspondance politique du Brésil, vol. 13, despachos de 20/7/1831 e 30/9/1831, Archives du Ministère des Affaires Etrangères, Paris. 
Mas um dos pontos sensíveis, onde se fazia mais visível a presença de manifestações públicas, era justamente nos quarteirões do comércio da cidade. Eram constantes nestes lugares as aglomerações, a presença ruidosa de grupos que ocupavam as ruas não raro com proposições explicitamente políticas. Explica-se: o comércio era um dos pontos nevrálgicos do período pós-independência, pois a permanência do monopólio dos portugueses nesta atividade gerava conflitos constantes. ${ }^{9}$

Os testemunhos da época se repetem sobre esta "agitação" nas ruas do comércio. Como no caso deste jornal típico da imprensa de opinião da época:

"Ainda sairam do Armazém do Sr. Monteiro na rua nova de S. Francisco, homens armados de paus para massacrarem brasileiros, como o fizeram em a noite portuguesa. Mas quando na rua dos ferradores, em casa do Sr. Brício, segundo é fama pública, esse Sr. Português, em sua diária companhia, ataca a Constituição, insulta a Câmara dos Srs. Deputados, etc., etc., [...] merecem tais homens pelo contrário as piedosas vistas, e inatas clemências do mesmo Sr. Governo do Brasil [...]."

Ou ainda outro periódico, de tendências políticas distintas do anterior:

"Viram-se então em vários lugares da cidade, especialmente nas ruas do corpo do comércio, alguns magotes de homens (quase todos da classe ínfima da sociedade) armados de paus, chuços e facas, que ameaçavam tomar deste fato vingança nos europeus, e que, segundo nos consta, feriram e espancaram com efeito a algumas pessoas." 11

Na primeira citação, vinda de um redator identificado ao chamado liberalismo Exaltado, aparecem os portugueses que se posicionavam

9 Sobre este assunto ver as dissertações de Mestrado em História de Lenira Menezes Martinho Organização do trabalho e relações sociais no interior das firmas comerciais do Rio de Janeiro na primeira metade do século XIX (Universidade Federal Fluminense, 1977) e de Gladys Sabina Ribeiro "Cabras" e "pés-dechumbo": os rolos do tempo: o antilusitanismo na Cidade do Rio de Janeiro: (1890-1930) (Universidade Federal Fluminense, Niterói, 1987). Sobre as manifestações antilusitanas consultar o livro de Barbosa Lima Sobrinho Desde quando somos nacionalistas? (Rio de Janeiro: Civilização Brasileira, 1963).

11 Cf. Aurora Fluminense, n. 478, 29 abr. 1831. 
contra o liberalismo constitucional do Brasil e a origem de tais manifestações de rua estariam nos armazéns, isto é, na esfera da atividade comercial da cidade. Na segunda citação, oriunda de outro redator vinculado ao liberalismo Moderado, destacam-se os protagonistas da "classe ínfima" da sociedade. Mas em ambos os casos aparece a questão da nacionalidade: os portugueses ou as camadas pobres como ameaça à ordem nacional que se pretendia consolidar. E o que está em questão nestes dois casos são atividades políticas que se faziam nas ruas e fora do controle imediato do poder monárquico. Ou seja, a política que se fazia nas ruas como ameaça à uma ordem que deveria ser baseada sobre os valores modernos de liberalismo, inclusive de liberdade individual (privada), propriedade e segurança. Ainda aqui se reforça a percepção deste "comércio" entre a esfera privada e os espaços públicos na capital imperial no decorrer do processo de independência.

Se os liberais Exaltados denunciavam sobretudo as manifestações dos portugueses antibrasileiros, a preocupação de outros setores era geralmente voltada para as "classes ínfimas", que apareciam com predominância neste espaço da rua. Cidade, cidadania e nacionalidade eram questões que se imbricavam.

O representante diplomático francês no Rio às vésperas da independência, o coronel Maler (ultramonarquista convicto, eivado de preconceitos raciais), traça o seguinte quadro:

“[...] au milieu de ces blancs qui paraissaient très consternés j'ai vu des groupes de nègres et de négresses allant dans tous les sens et poussant des cris d'allégresse en se disant à haute voix aux uns comme aux autres: 'Les chasseurs tuent tous les blancs dans la ville'. Tous les blancs ferment les portes de leur maison'."'12

A crer neste testemunho, o Rio de Janeiro em 1821 estaria prestes a presenciar uma revolução de escravos como no Haiti alguns anos antes. As vozes que pairam sobre a cidade, segundo este diplomata, eram as dos escravos, que apareciam em determinados momentos

12 Correspondance politique du Brésil, volume 1, despacho de 05/06/1821, Archives du Ministère des Affaires Etrangères, Paris. Traduçāo livre: "[...] em meio a estes brancos que pareciam muito consternados vi grupos de negros e negras indo para todos os lados e lançando gritos de alegria e falando alto entre eles: 'Os caçadores matam todos os brancos na cidade'. Todos os brancos fecham as portas de suas casas." 
como senhores do espaço urbano. Impressão recorrente nos momentos de grande medo nos países escravistas. Eram clamores que despertavam temores. Os gritos e vozes nas ruas constituem, aliás, uma forma de ocupação dos espaços públicos, ainda que simbólica e efêmera, mas muitas vezes eficaz e impressionante. É o que se chama de "Voz Popular", tantas vezes referida em fontes documentais dos séculos XVIII e XIX.

Dez anos mais tarde, nos conflitos de rua que antecederam a abdicação de D. Pedro I, por exemplo, é expressivo o testemunho do conde de Gestas, embaixador francês na capital:

"Le 15 matin, la ville présentait un spectacle effrayant; les Boutiques sont fermées, des rassemblements de nègres et de mulâtres armés parcouraient les rues tenant les propos les plus incendiaires et commettant des désordres, des militaires à la débandade tiraient sur les passants; d'autres entraient dans les magasins pour voler: plusieurs de ces magasins appartenant à des Portugais ont été pillés et leurs maîtres égorgés." ${ }^{13}$

Descontados os possíveis exageros do diplomata francês, sabe-se que em 1831, referente a estes acontecimentos (Noite das Garrafadas, abdicação de D. Pedro I, etc.) o ministério da Justiça registrou 850 presos no Rio de Janeiro devido a tais manifestações. ${ }^{14}$ A citação acima - como muitas outras da época - revela que em determinados momentos os "donos" do espaço urbano pertenciam às camadas subalternas da população do ponto de vista étnico e social. Ou seja, eram também atores políticos no cenário urbano, cuja atuação tocava de perto as decisões da Corte.

${ }^{13}$ Correspondance politique du Brésil, volume 13, despacho de 20/07/1831, Archives du Ministère des Affaires Etrangères, Paris. Tradução livre: "Na manhã do dia 15 a cidade apresentava um espetáculo aterrorizante; as lojas estão fechadas, grupos de negros e de mulatos armados percorriam as ruas com as imprecaçōes mais incendiárias e cometendo desordens; militares em debandada atiravam sobre os transeuntes; outros entravam nas lojas para roubar; muitas destas lojas pertencendo a portugueses foram pilhadas e seus donos degolados."

14 Números citados no documento Brasil. Ministério da Justiça. Ministro Diogo Antonio Feijó. Relatório do anno de 1831 apresentado à Assembléia Geral Legislativa na Sessão ordinária de 1832. Para uma abordagem inicial dos atores políticos na época em questão, ver Olavo Brasil Lima Jr. e Lucia Maria Gomes Klein, "Atores políticos do Império" (Dados, n. 7, Rio de Janeiro, 1970). 
Os espetáculos da monarquia anteriormente lembrados se enquadram naquilo que se passava então a chamar de forma antiga de se fazer política, oriunda dos Antigos Regimes europeus, marcados pela presença de multidões nas ruas das cidades dentro do quadro dos regimes absolutistas, nos quais se inseriam os domínios nas Américas. No período colonial ocorriam também algumas destas turbulências de rua fora do controle das autoridades. Mas o que começa a se marcar no Brasil dos anos 1830 é que algumas destas manifestações na rua (da mesma forma que os meetings que se desenvolviam com o cartismo inglês) passam a ter também uma conotação ligada à cidadania, à mudança de soberania, à interferência na vida pública fora da esfera de controle das autoridades vigentes, em outras palavras, começa a se esboçar uma dimensão vinculada à modernidade política, onde as reuniões se fazem em nome da soberania popular ou nacional. ${ }^{15}$

Nesta época surgem as primeiras batalhas jurídicas no sentido de se poder utilizar formalmente as ruas e praças como lugar de manifestação cívica, fora da iniciativa oficial. Em 1830, por exemplo, para festejar o oitavo aniversário da proclamação da independência, Ezequiel Correia dos Santos, redator do jornal Nova Luz Brazileira (identificado aos chamados liberais Exaltados) pede autorização para preparar uma comemoração no Passeio Público. O chefe da polícia nega a pretensão. Outro redator, Evaristo da Veiga (Aurora Fluminense, expressão dos chamados liberais Moderados) protesta contra tal proibição e pergunta: se o governo sempre permitiu outras festas de rua como a do Espírito Santo, de Nossa Senhora da Glória e a dos militares no Campo de Santana, por que então impedir a comemoração da independência? ${ }^{16}$ Este episódio é revelador do conflito entre duas formas de sociabilidade nas ruas: uma já tradicional, como cerimônias religiosas ou festas de corporações e outra no sentido da modernidade política, na perspectiva de indivíduos livres (cidadãos) que se reuniam em público como expressão da soberania nacional ou popular.

\footnotetext{
15 Sobre a passagem para a modernidade política na primeira metade do século XIX ver o interessante trabalho de François-Xavier Guerra Modernidad e independencias (Madri: Mapfre, 1992). Para o conceito de modernidade nacional ver também Eric Hobsbawn Nações e nacionalismo desde 1780 (Rio de Janeiro: Paz e Terra, 1991).
}

16 Aurora Fluminense, n. $382,1^{9}$ set. 1830. 
Vale lembrar apenas como referência que os quarteirôes do comércio também congregavam as elites letradas da época, em pontos de sociabilidade mais ou menos informais como os locais de venda da imprensa, livrarias, boticas e cafés.

\section{A "disputa" das praças}

As movimentações urbanas não se davam apenas nos quarteirões do comércio, mas também nas praças e largos que existiam por toda a cidade. Qual a dimensão política das diferentes ocupações destes espaços urbanos?

Em primeiro lugar destacava-se a Praça do Paço, que equivalia a uma "Grande Praça" ou "Praça Real" européia, em forma de um quadrado, com uma face aberta para o mar. Nela ficava o Palácio do Rio de Janeiro, mais tarde Paço Imperial, onde funcionava a sede da Coroa. A movimentação era constante, não só pelas atividades administrativas que envolviam o exercício do poder, mas também pelo fato do local estar em frente ao porto marítimo, onde desembarcavam passageiros e mercadorias. Dos balcões e janelas do Palácio muitas vezes D. Pedro acenava ou discursava para a multidão - como no célebre Dia do Fico em fevereiro de 1822. Este gesto - as autoridades se dirigem ao "Povo" do alto do balcão e são assim aclamadas ou aplaudidas - faz parte de operação política típica do absolutismo. Esta praça se marcava assim por uma utilização tradicional, lugar de encontro entre o monarca e os súditos, sem a mediação de outras instâncias de representatividade. Era um centro nevrálgico da capital imperial. ${ }^{17}$

Logo esta Praça do Paço veria sua importância no cenário urbano ser dividida com outro local, a Praça do Rocio. O que caracterizava o local era a presença do principal (e por algum tempo único) teatro da cidade, o Teatro São Pedro de Alcântara. O teatro, nestes anos 18201840, teve uma característica singular: na falta de lugar determinado para reuniões públicas abertas fora da convocação das autoridades ele tornou-se um lugar de encontro mais ou menos espontâneo. Sem ser

17 Procurando situar estas praças na memória histórica urbana, lembro que com o advento da República a Praça do Paço, que marcava este exercício de poder da monarquia, foi rebatizada de Praça XV de Novembro, como que para exorcizar a imagem que a marcara até então. 
um local de deliberação, a sala de espetáculos passou a ser, pela apropriação do público que a procurava, um espaço favorecendo a expressão de vontades e opiniões abertamente políticas. No interior da sala, formavam-se claques e grupos que se afrontavam com gritos e "palavras-de-ordem". A platéia roubava a cena e se convertia em ator. Do lado de fora, nos dias de apresentação, uma multidão se concentrava em torno do teatro, repercutindo e reforçando as manifestações. O público extrapolava os limites do prédio e a praça virava um coral, voz pública e coletiva. A Família Imperial tinha camarote e também buscava se apropriar do espaço. Por isso, o local era alvo de disputas políticas, chamadas também de "lutas simbólicas". O Rocio era uma espécie de "Praça do Povo". Informalmente chamada de Praça do Teatro, foi rebatizada como Praça da Constituição. ${ }^{18}$

Uma terceira "praça" entra nestas transformações da utilização dos espaços públicos: o Campo de Santana, onde estavam importantes unidades militares, como os Quartéis de Infantaria e da Cavalaria, entre outros. Encontrava-se também ali o Conselho Municipal. Assim, o Campo equivalia a uma "Praça d'Armas" e também ao "Cabildo", ou seja, predomínio do elemento militar e do poder civil local. Em termos de espaço urbano, os protagonistas passam a se referir ao local como expressão coletiva da "tropa" e do "povo". Não só os protagonistas, mas pesquisadores reproduzem com freqüência tais categorias. Foi como locus privilegiado de "tropa" e "povo" que no Campo de Santana houve a manifestação pública que resultou na abdicação de D. Pedro I em 1831. O lugar chegou a ter também diferentes nomes, como Campo de Marte (referente à inspiração neo-clássica) e Campo da Honra (alusão ao movimento contra D. Pedro I). ${ }^{19}$

18 Hoje se chama Praça Tiradentes, em homenagem ao "herói popular". Mas no meio da praça há uma estátua eqüestre de D. Pedro I. E, mais recentemente, o local foi cercado com grades - transformando sua utilização enquanto espaço público. Para o conceito de "lutas simbólicas", v. Roger Chartier, "Le monde comme représentation” (Annales E.S.C., Paris, n. 6, nov./dez. 1989). As lutas nem sempre ficavam no terreno simbólico neste Teatro: em 28 de setembro de 1831 houve violento conflito com mortos e feridos.

19 Da mesma forma a Proclamação da República. Hoje o local tem o duplo nome de Praça da República e Campo de Santana, num hibridismo que busca legitimar as inovações numa tradição. Ali foi erguido o prédio do Ministério da Guerra, que hoje sedia o Comando Militar do Leste e também se preserva como memória histórica a casa onde morava o marechal Deodoro da Fonseca. O elemento da "tropa" parece ter predominado sobre o do "povo" em termos de memória histórica. 
Vale lembrar também a Praça das Execuções, situada perto do mar, nas imediações do Caju, e que desapareceu não só fisicamente, mas de grande parte dos registros da memória histórica. Era, entretanto, um local de intensa atividade pública, pois as execuçóes da pena de morte eram acompanhadas de cortejos, desfiles e de grande curiosidade por parte da população.

Havia um local significativo e híbrido em termos de espaços públicos: a chamada Praça do Comércio. Na verdade, era uma galeria coberta, cujas entradas permitiam livre acesso: ao mesmo tempo fechada e aberta. Este imóvel, construído em 1820 pelo arquiteto francês Grandjean de Montigny, abrigava a Bolsa e o Tribunal do Comércio. Localizado na beira do mar, ao lado da Alfândega e a poucos passos do Palácio do Rio de Janeiro. As grandes salas, com janelas largas e cúpulas bem altas davam-lhe a condição de "praça" e a movimentação era grande ali não só de dia, mas também à noite. Tal como o teatro, foi um local apropriado por diversas camadas da população e não eram apenas os comerciantes que o freqüentavam. Ali realizava-se, em fevereiro de 1821 , a reunião dos eleitores primários (o voto era censitário e indireto) que passaram a de certo modo desafiar a soberania de D. João VI e do príncipe Pedro - que enviaram tropas que entraram atirando - episódio conhecido como "massacre da Praça do Comércio". ${ }^{20} \mathrm{O}$ imóvel ficou fechado alguns anos depois do conflito. Reaberto, as autoridades passaram a regulamentar o uso deste espaço. Foi elaborado em 1834 um Regulamento para o local, certamente uma das primeiras praças no Brasil a ter seu acesso regulamentado - signo de modernização e racionalização dos espaços públicos. Segundo este Regulamento, a "praça" deveria ficar aberta das 9 horas da manhã até o pôr do sol. Apenas os membros da recém criada Sociedade dos Assinantes da Praça tinham direito de freqüentar as dependências, onde encontravam registros dos preços de mercado, de controle da entrada e saída de navios e jornais periódicos para a leitura. Temos então uma praça comercial, dentro da polissemia da palavra "praça", que comporta diversos significados. Com esta utili-

Cf. Ruth Kato Revoltas de rua: o Rio de Janeiro em três momentos (1821-18281831) (Mestrado de História, Universidade Federal do Rio de Janeiro, 1988). O imóvel da "Praça" foi recentemente restaurado e abriga a Casa França-Brasil, local de exposições artísticas temporárias - sem maiores indicações dos episódios violentos e famosos (na época) que ali ocorreram. 
zação mais homogênea o local perde o hibridismo entre aberto e fechado e passa a ser um ambiente reservado, mais coerente com os "novos tempos" que se pretendia alcançar.

Outro espaço urbano importante eram os Largos. O que caracterizava tais Largos era a interligação com igrejas e capelas. No Largo do Capim, ficava a Igreja do Bom Jesus; no Largo de São Domingos duas igrejas, uma do mesmo nome do local e a de Nossa Senhora da Conceição; no Largo de São Francisco de Paula também a igreja que deu nome ao local e ainda a Nossa Senhora do Rosário; no Largo da Ajuda também se repetia o mesmo fenômeno, com o Convento Nossa Senhora da Ajuda; no Largo da Carioca, o Convento Santo Antônio e a capela da Ordem Terceira de São Francisco de Assis; no Largo do Moura, a Igreja de Santana. ${ }^{21}$ Ou seja, eram espaços existentes em função das atividades religiosas.

\section{As transformações políticas e os espaços urbanos}

Assistia-se então a uma verdadeira "disputa" entre praças, disputa pela proeminência política no espaço urbano - que se tornava ainda mais significativa por se tratar da capital do Império. As praças aparecem como espaços abertos e de certo modo em aberto, isto é, como passíveis de serem apropriados por determinadas interferências cole-

${ }^{21}$ Na identificaçāo das praças e largos utilizei e comparei diversos mapas da época (citados aqui com o código da Bibliothèque Nationale de France), como: Esquisse de la ville et du port de Rio de Janeiro, gravé par De Cardieu l'aîné, 1807, Cote GeFF8689; Mapa geografico, historico y politico del Brasil, des. et gr. par J.M. Darmet, écrit par Hacque, Paris, J. M. Darmet, 1826, Cote GeC8954; Plan de la baie de Rio de Janeiro, levé en 1826 et 1827, par M. Barral. Dépôt Général de la Marine, 1829, Cote GeCC1192; Plan de la ville de S. Sebastiäo do Rio de Janeiro. 1820. Gravé par Michel. Cote GeD6646; Plan von Rio de Janeiro, Lith W. Poluda, pl. 143, 1844, Cote GeFF6439; Planta da Cidade de São Sebastião do Rio de Janeiro. Reduzida que se publicou no anno de 1812 en 1817. GeD914; Rio de Janeiro, 1757, en couleurs, Cote GeD3998; Rio de Janeiro vers 1825 (plan inachevé). Cote GeC3562. Para um histórico das praças e logradouros do Rio de Janeiro há vasta bibliografia. Cito aqui obra útil de síntese e com base documental: Vivaldo Coaracy, Memórias da cidade do Rio de Janeiro (Rio de Janeiro: José Olympio, 1955). Entre os estudos clássicos temos José Vieira Fazenda Antiqualhas e Memórias do Rio de Janeiro (5 v., Rio de Janeiro, 1925-1927). 
tivas, resultando daí indentidades próprias para cada um destes locais - identidades que se fixavam, mas tendiam a se transformar, como decorrência desta mesma "disputa". Os Largos, em contrapartida, pareciam ter papel mais fixado, como se fossem mais enraizados em estruturas urbanas criadas por instituição sólida e presente nos hábitos da população, como a Igreja - embora aí as apropriações e transformações pudessem ocorrer no âmbito mesmo dos festejos e outras manifestações culturais.

Desta forma, percebe-se que os espaços públicos na cidade imperial do Rio de Janeiro tinham uma característica tradicional. Eram como a base física das "três ordens" do Antigo Regime: a Nobreza guerreira, o Clero e o Povo..$^{22}$ Sobretudo das duas primeiras, cujas praças e largos existiam predominantemente em função da Coroa, dos militares e da Igreja - cabendo ao "Povo" as tentativas de apropriação de outros espaços, que assim se tornavam híbridos. Fosse um "Povo" à moda antiga, que se expressava na época colonial e continuava neste início da era nacional, fosse "Povo" na acepção moderna, não apenas os comerciantes, seus agregados e clientes, mas também diferentes camadas da população que iam marcando sua presença na cena urbana, como membros das elites letradas e mesmo setores da "plebe". Era o movimento de passagem para a condição de súditos-cidadãos.

Sobre a base urbana tradicional, e numa sociedade escravista, diferentes atores políticos e sociais começavam a atuar e conceber sua atuação dentro das perspectivas da modernidade política, dos liberalismos, da livre expressão individual, do constitucionalismo, das noções de soberania popular e nacional e de suas formas de representatividade, enfim, na inserção como cidadãos. Desta maneira a cidade condicionava o enredo político e cultural e, ao mesmo tempo, ia sendo transformada pelas interferências dos diferentes atores sociais e políticos. Ou seja, as concepções políticas e culturais transformavam a cena pública e não eram apenas transformadas por esta. E estes primeiros esboços de modernidade, no plano cultural e político, precedem as transformações urbanas que ocorreriam décadas mais tarde.

22 Para esta concepção tríplice que, na Idade Média, os protagonistas tinham da sociedade em que viviam (e que permaneceria ainda em começos do século XIX em determinados países como um dos pilares da ordem jurídica ocidental), ver Georges Duby Les trois ordres ou l'imaginaire du féodalisme (Paris: Gallimard, 1978). 
Do mesmo modo pode-se perceber que as ruas da capital imperial eram locus privilegiado de se fazer política, mesmo para aqueles que não eram privilegiados sociais e não interferiam diretamente nas decisões do poder. As ruas da Cidade-Corte eram cena de poder, ponto essencial para a organização da nacionalidade que se elaborava. Ruas ocupadas numa mesma época de diferentes maneiras (celebrações dinásticas e religiosas, festejos diversos, "desordens" e revoltas, vozes, clamores, tentativas de manifestações cívicas), revelando assim a pluralidade de tempos num mesmo tempo histórico e apontando para transformações dos espaços públicos em suas dimensões políticas, isto é, de relações de poder, como fatores importantes para a elaboração da história das cidades que, afinal, são elementos bases na construção de uma nação. Cidadania e nacionalidade se entrelaçam. As praças seriam do "Povo", como pregaria nos anos 1870 o Romântico Castro Alves? E de que "Povo"? São questões ainda por resolver. 